\title{
MAGEA3 Positive
}

National Cancer Institute

\section{Source}

National Cancer Institute. MAGEA3 Positive. NCI Thesaurus. Code C135575.

An indication that melanoma-associated antigen 3 expression has been detected in a sample. 